Trab. Ling. Aplic., Campinas, 49(2): 455-479, Jul./Dez. 2010

\title{
LETRAMENTO METAMIDIÁTICO: TRANSFORMANDO SIGNIFICADOS E MÍDIAS*
}

\author{
METAMEDIA LITERACY: TRANSFORMING MEANINGS AND MEDIA
}

\author{
JAY L. LEMKE**
}

\begin{abstract}
RESUMO: Toda semiótica é semiótica multimídiática e todo letramento é letramento multimidiático. A análise da semiótica multimidiática me levou a refazer algumas perguntas antigas de maneiras novas e a começar a olhar para a história da escrita, do desenho, do cálculo e da mostra visual de imagens em uma perspectiva diferente. Faz um bom tempo que as tecnologias do letramento não são tão simples quanto a caneta, a tinta e o papel. E na era da imprensa, assim como antes dela, o letramento raramente esteve atrelado de forma estrita ao texto escrito. Muitos dos gêneros do letramento, do artigo da revista popular ao relatório de pesquisa científica, combinam imagens visuais e texto impresso em formas que tornam as referências entre eles essenciais para entendê-los do modo como o fazem seus leitores e autores regulares. Nenhuma tecnologia é uma ilha. Conforme nossas tecnologias se tornam mais complexas, elas se tornam situadas em redes mais amplas e longas de outras tecnologias e de outras práticas culturais.

Palavras chave: letramento multimidiático; letramento metamidiático; semiótica multimidiática.
\end{abstract}

ABSTRACT: All semiotics is multimedia semiotics, and all literacy is multimedia literacy._Analyzing multimedia semiotics has led me to ask some old questions in new ways and to begin to see the history of writing, drawing, calculating, and displaying images visually in a different light. It's been a long time since the technologies of literacy were as simple as pen, ink, and paper; and in the era of print, as before, literacy has rarely meant verbal text alone. Many of the genres of literacy, from the popular magazine article to the scientific research report, combine visual images and printed text in ways that make crossreference between them essential to understanding them as their regular readers and writers do. No technology is an island. As our technologies become more complex they find themselves situated in larger and longer networks of other technologies and other cultural practices

Keywords: multimedia literacy; metamedia literacy; multimedia semiotics.

\section{TRANSFORMANDO TEORIAS DE LETRAMENTO E SOCIEDADE}

Letramentos são legiões. Cada um deles consiste em um conjunto de práticas sociais interdependentes que interligam pessoas, objetos midiáticos e estratégias de construção de significado (LEMKE, 1989a; GEE, 1990; BEACH, LUNDELL, 1998). Cada um deles é parte integral de uma cultura e de suas subculturas. Cada um tem um papel em manter e transformar

"Original em inglês intitulado "Metamedia Literacy: Transforming Meanings and Media" disponível em http://www-personal.umich.edu/ jaylemke/jll-new.htm. Agradecimentos ao autor pela autorização para tradução.

**Department of Educational Studies University of Michigan. <jaylemke@umich.edu> 
a sociedade, porque os letramentos produzem ligações essenciais entre significados e fazeres. Os letramentos são, em si mesmos, tecnologias e nos dão as chaves para usar tecnologias mais amplas. Eles também produzem uma chave entre o eu e a sociedade: o meio através do qual agimos, participamos e nos tornamos moldados por sistemas e redes 'ecossociais' mais amplos (veja exemplos abaixo e em LEMKE, 1993a, 1995b). Os letramentos são transformados na dinâmica desses sistemas de auto-organização mais amplos e nós nossas percepções humanas, identidades e possibilidades - somos transformados juntamente com eles.

Este, pelo menos, é o estado da arte da forma como esquematizaria hoje. Deixem-me tentar apontar alguns detalhes que são particularmente relevantes para as nossas preocupações aqui. A noção de 'letramento' assim colocada parece-me muito ampla para ser utilizável. Não acho que possamos defini-la de forma mais precisa do que um conjunto de competências culturais para construir significados sociais reconhecíveis através do uso de tecnologias materiais particulares. Uma definição como esta dificilmente distingue o letramento de uma competência para cozinhar ou escolher o que vestir, exceto pelos recursos semióticos particulares usados para construir significados (o sistema linguístico vs. o sistema culinário ou de moda) e os artefatos materiais particulares que mediam esse processo (sons vocais ou sinais escritos vs. comidas, roupas). Houve um tempo, talvez, em que podíamos acreditar que construir significados com a língua de algum modo era fundamentalmente diferente ou poderia ser tratado separadamente da produção de significados com recursos visuais ou padrões de ação corporal e interação social. Hoje, no entanto, nossas tecnologias estão nos movendo da era da 'escrita' para a era da 'autoria multimidiática'(ver PURVES, 1998 e BOLTER, 1998), em que documentos e imagens de notações verbais e textos escritos propriamente ditos são meros componentes de objetos mais amplos de construção de significados. Os significados das palavras e imagens, lidas ou ouvidas, vistas de forma estática ou em mudança, são diferentes em função dos contextos em que elas aparecem - contextos que consistem significativamente de componentes de outras mídias. Os significados em outras mídias não são fixos e aditivos (o significado da palavra mais o significado da imagem), mas sim, multiplicativos (o significado da palavra se modifica através do contexto imagético e o significado da imagem se modifica pelo contexto textual) fazendo do todo algo muito maior do que a simples soma das partes (ver LEMKE 1994a, 1998). Além disso, todo letramento é letramento multimidiático: você nunca pode construir significado com a língua de forma isolada. É preciso que haja sempre uma realização visual ou vocal de signos linguísticos que também carrega significado não-linguístico (por ex.: tom da voz ou estilo da ortografia). Para funcionarem como signos, os signos devem ter alguma realidade material, mas toda forma material carrega, potencialmente, significados definidos por mais de um código. Toda semiótica é semiótica multimídia e todo letramento é letramento multimidiático.

A tradição cultural europeia, assim como outras, reconheceu há algum tempo estes princípios multimidiáticos e deles tem feito uso mesmo em textos impressos comuns (cf. OLSON, 1994;ALPERS, 1983; BELLONE, 1980; EISENSTEIN, 1979), seja através de ilustração manuscrita ou pelo uso de diagramas em escrita técnica. Contudo, tem havido um certo 'logocentrismo' moderno (DERRIDA, 1976) que identificou somente na língua um meio confiável para o pensamento lógico, e na língua escrita, inicialmente, o primeiro meio de 
autorizar o conhecimento e, posteriormente, o meio mais avançado de capacidade cognitiva (ver OLSON, 1994 para uma reprise destes argumentos e LEMKE, 1995c, para uma crítica).

Se tivermos que especificar com exatidão quais recursos semióticos e quais materiais tecnológicos definem um letramento particular, então teremos tantos letramentos quanto o número de gêneros multimidiáticos (cf. GEE, 1990). Estes talvez possam ser ainda subdivididos (e da mesma forma o número de letramentos funcionais possam ser multiplicados) considerando-se se devem ser incluídas tanto a competência com as tecnologias de produção quanto com as tecnologias de uso. Quando a escrita requeria caneta e papel ou máquina de datilografia, e a leitura requeria apenas o livro (e talvez um par de óculos) era simples manter essas distinções. Hoje, no entanto, se você desejar ler um hipertexto (ver BOLTER, 1998) ou escrevê-lo, precisará praticamente das mesmas tecnologias de hardware e software, e precisará tanto de habilidades de autoria novas quanto de novas habilidades de interpretação para usá-las.

Finalmente, no espírito do trabalho de Latour $(1987,1993)$ sobre 'redes de ator' no estudo das tecnologias na sociedade, precisamos considerar outras pessoas como parte da ecologia tecnológica das práticas de letramento. (Latour constrói redes sociais tanto dos atores humanos quanto dos 'atores' não humanos, tais como artefatos técnicos em uma ecologia social de práticas culturais). A rede de interações que torna significativo um texto ou um objeto multimidiático não se limita àquelas entre o autor ou usuário e o objeto, mas deve também incluir aquelas com professores, colegas e comunidades de pessoas que assumem práticas que tornam uma combinação sígnica significativa. Isolados de todas as interações, os humanos não aprendem a falar ou a escrever. Por mais que a ideologia do individualismo possa construir o estereótipo do escritor ou leitor solitário, o fato de os textos e signos serem socialmente significativos é o que confere a eles a sua utilidade e os torna possíveis. Aquilo que parece ser o mesmo texto ou gênero multimidiático não é funcionalmente o mesmo quando no papel ou na tela, segue diferentes convenções de significado e requer diferentes habilidades para que seu uso seja bem sucedido, quando funciona em diferentes redes sociais para diferentes objetivos, como parte de diferentes atividades humanas. Um letramento é sempre um letramento em algum gênero e deve ser definido com respeito aos sistemas sígnicos empregados, às tecnologias materiais usadas e aos contextos sociais de produção, circulação e uso de um gênero particular. Podemos ser letrados em um gênero de relato de pesquisa científica ou em um gênero de apresentação de negócios. Em cada caso as habilidades de letramento específicas e as comunidades de comunicação relevantes são muito diferentes.

No estudo do letramento na linguagem escrita, há ainda debate considerável sobre o quão importante é o fato de os sinais materiais da escrita serem relativamente mais permanentes ou mais evanescentes, como são organizados no espaço e no tempo e o que conta como 'escrita' (Matemática? Braille? Vídeos da Língua Americana de Sinais?)_Algumas destas questões permanecem como questões de interesse no caso de alguns gêneros e tecnologias, mas poucas delas já foram reconceitualizadas no contexto das novas tecnologias multimidiáticas (veja HARRIS 1995 e LEMKE 1997).

Também precisamos recontextualizar as relações entre os letramentos e as sociedades em que eles operam e o papel das pessoas nesses processos mais amplos (por exemplo, OLSON 1994, LEMKE 1995c). Precisamos renovar nossas velhas formas de tratar destes 
fenômenos. Não é mais suficiente imaginar que as sociedades são constituídas por indivíduos isolados, ligados imprevisivelmente através de contatos sociais voluntários, com 'mentes' individuais e autônomas de algum modo dissociadas do mundo material. Não podemos continuar pensando que exista apenas um 'letramento' ou que isto seja apenas o que as mentes individuais fazem quando confrontadas com um símbolo de cada vez.

Toda vez em que construímos significado durante a leitura de um texto ou interpretação de um gráfico ou figura, nós o fazemos através da conexão dos símbolos à mão com outras imagens lidas, ouvidas, vistas ou imaginadas em outras ocasiões (o princípio da intertextualidade genérica; cf. LEMKE 1985, 1992, 1995a). As conexões que fazemos (o tipo de conexão e os textos e imagens a que efetivamente nos conectamos) são parcialmente individuais, pois são características da nossa sociedade e do lugar que nela ocupamos: nossa idade, nosso gênero, nossa classe econômica, nossas afiliações, nossas tradições familiares, nossas culturas e subculturas.

Letramentos são sempre sociais: nós os aprendemos pela participação em relações sociais; suas formas convencionais desenvolveram-se historicamente em sociedades particulares; os significados que construímos com eles sempre nos liga a uma rede de significados elaborada por outros.

Letramentos são legiões. Cada registro, gênero ou formação discursiva diferente (HALLIDAY, 1977, 1978; MARTIN, 1992; BAZERMAN, 1988, 1994; FOUCAULT, 1969; LEMKE, 1995b; GEE, 1990) é produto de alguma subcomunidade específica na realização de seus negócios particulares. Ser um falante nativo, saber a gramática, buscar no dicionário não é suficiente para se entender- os textos de comunidades específicas da forma como seus membros os entendem, a não ser que também conheçamos seus contextos de uso. Por exemplo, narrações de partidas de torneios de críquete são quase que incompreensíveis para mim, ainda que eu tenha um conhecimento rudimentar dos termos e regras e uma ou duas horas como espectador. Tenho dificuldade em entender mesmo quando assisto a uma partida enquanto ouço o comentário. Não sou suficientemente membro dessa comunidade, não tenho experiência suficiente, não ouvi comentários suficientes, nem vi partidas suficientes, ou compreendi as estratégias do jogo, a cultura dessa comunidade. Não é diferente se você se deparar com um artigo de pesquisa sobre cosmologia quântica ou sobre desenvolvimento biotecnológico, ou um relatório técnico sobre os reparos técnicos necessários em uma estação de energia elétrica, ou um 'mangá' japonês. Não importa se a mídia é a voz ou o vídeo, diagrama ou texto. O que importa é como construir significado da forma como os nativos o fazem.

Letramentos não podem ser entendidos como atos passivos. Compreender um texto impresso é um processo complexo e ativo de construção de significado que não difere tanto do processo de escrita do texto original (por exemplo, de editar e modificar um rascunho ou de reunir notas em um texto coerente). A leitura e a escrita são processos de construção de significados do mesmo tipo. Esses processos não são, de forma alguma, o 'inverso' um do outro (LEMKE, 1989a; HARRIS, 1995). Eles só diferem nas condições situacionais: os outros jogadores humanos ou inanimados com os quais interagimos para construir nossos significados - sejam eles parceiros de produção escrita ou marcas no papel.

Faz um bom tempo que as tecnologias do letramento não são tão simples quanto a caneta, a tinta e o papel. E na era da imprensa, assim como antes dela, o letramento raramente 
esteve atrelado de forma estrita ao texto escrito. Muitos dos gêneros do letramento, do artigo da revista popular ao relatório de pesquisa científica, combinam imagens visuais e texto impresso em formas que tornam as referências entre eles essenciais para entendê-los do modo como o fazem seus leitores e autores regulares. Nenhuma tecnologia é uma ilha. Toda prática letrada de construção de significado estabelece relação de interdependência com habilidades que vão desde a navegação no teclado até a virada de uma página, da composição à encadernação, da edição às venda e distribuição (no caso das tecnologias impressas). Conforme nossas tecnologias se tornam mais complexas, elas se tornam situadas em redes mais amplas e longas de outras tecnologias e de outras práticas culturais (LATOUR, 1993).

A publicação de si mesmo na Rede Mundial de Computadores deve deixar de fora muitos intermediários da velha imprensa, humanos e máquinas, mas além de simples habilidades de escrita e digitação, você precisa ser capaz de operar o software e o hardware para ter seu trabalho apropriadamente formatado em HTML, armazenado em um servidor, conectado à internet. Alguém precisa escrever e atualizar esses programas, alguém precisa projetá-lo, manufaturá-lo, vendê-lo e entregar o hardware, configurá-lo, manter a rede, desenvolver protocolos, oferecer assistência e serviço técnico. Como um processador universal de informação, o mesmo computador pode servir para muitos destes propósitos, o que faz com que o processo pareça mais simples. Porém, as pessoas precisam saber de muito mais, tanto materialmente, quanto semioticamente, para usar um computador e projetar e manter todo esse sistema de práticas. Algumas pessoas, de algum modo, precisam manipular mais tipos diferentes de questões em diferentes formas. Precisamos saber como fazer diferentes tipos de coisas novas (coletiva e individualmente).

Os letramentos não podem ser analisados adequadamente se consideramos apenas o que as pessoas fazem. Devemos compreendê-los como parte de sistemas mais amplos de práticas que dão coesão à sociedade, que fazem dela uma unidade de organização própria e dinâmica muito mais ampla do que o indivíduo. Na realidade, se pensamos que a palavra sociedade significa apenas pessoas, então precisamos de outro termo; um termo que, como ecossistema, inclua o ambiente completo: máquinas, prédios, cabos, satélites, alicerces, esgotos, fazendas, vida de inseto, bactérias... Tudo aquilo com que temos relações de interdependência para sermos a complexa comunidade que somos. Não poderíamos ser a comunidade que somos se não fizéssemos o que fazemos, e a maior parte do que fazemos depende não apenas de propriedades físicas e biológicas de todos estes parceiros de sistema, mas do que eles significam para nós.

De um ponto de vista dinâmico, todo o sistema do qual estamos falando, este através do qual precisamos analisar as mudanças nos letramentos e tecnologias, não é, de forma alguma, um sistema de coisas. Deve ser um sistema de processos interdependentes em que estas coisas participam, e que as integra, assim como o faz conosco, em um sistema. Processos biológicos e geológicos, atividades humanas e práticas sociais - consideradas como um sistema de acontecimentos interdependentes: um sistema 'ecossocial'(LEMKE, 1993a, 1995b). Nesse sistema, devemos seguir as ligações e as redes de interdependência: que práticas, onde e quando são interdependentes com que outras práticas em que lugar e quando. Crítico nestes processos (até o ponto em que as ações humanas importam para a dinâmica do sistema) são as práticas de construção de significado pelas quais nós, humanos, 
interpretamos, avaliamos, planejamos e cooperamos, incluindo nossas várias práticas de letramento. (Em geral, o limite entre práticas de letramento como essas e a construção de significado, ou práticas semióticas de significação, não é claro. Práticas de letramento centrais são geralmente distinguidas por 'código', língua e por mídia, espacial, visível e durável. Para esforços em lidar com as limitações dessas definições, ver Harris 1995, Lemke 1997.) Não precisamos mais separar nossas tecnologias materiais de modo tão radical como fizemos no passado como resultado de nossas 'estratégias cognitivas'. Pessoas-comcorpos participam em atividades e práticas, tais como a produção conjunta de um documento multimidiático na rede, em que nós e nossos recursos somos parceiros em ação; em que o que nós somos e a forma como agimos é tanto uma função daquilo que está à mão, quanto daquilo que está na cabeça. Este é o novo e poderoso ponto de vista sobre a atividade humana e a sociedade para o qual muitas disciplinas estão convergindo atualmente, tratem elas das redes de atores (LATOUR, 1987; LYNCH e WOOLGAR, 1990), da cognição situada ou social (LAVE, 1988; ROGOFF, 1990; HUTCHINS, 1995), do ecossistema semiótico (LEMKE, 1993a, 1995b), da atividade mediada (WERTSCH, 1991; ENGESTROM, 1990) ou das transgressões de ciborgues (HARAWAY, 1991; SOFIA, 1995; BRYSON e DECASTELL, 1996). Ao invés de teorizarmos relações causais de um domínio autônomo para outro (tecnologias para letramentos, letramentos para mentes, mentes para sociedades), se unirmos todos esses domínios como participantes na miríade de sub-redes de um sistema ecossocial, podemos dar explicações detalhadas de suas interdependências e da dinâmica autoorganizacional deste complexo sistema. Precisamos derrubar os limites artificiais que temos tentado criar entre o mental e o material, entre os aspectos individuais e sociais das pessoas e das coisas que interagem física e semioticamente com outras pessoas e coisas.

$\mathrm{Na}$ atualidade, novas tecnologias da informação estão mediando a transformação de nossas comunidades de construção de significado. Podemos nos comunicar, de forma inédita, com maior frequência e intimidade com as comunidades mais diversas em termos geográficos e culturais. Conferências online e grupos de discussão, frequentadores de chats e pioneiros dos MUDs e MOOs (HARRISON e STEPHEN, 1996; UNSWORTH, 1996; DAY et al., 1996) estão ampliando antigas comunidades e criando novas (RHEINGOLD, 1993). Pessoas que se correspondem poucas vezes ao ano e se encontram uma ou duas vezes em congressos podem estabelecer contato regular por e-mail, por internet em voz [voice internet] a baixo custo (assim esperamos), e talvez em breve, queiram a banda-larga e os reguladores, por vídeo-conferência. Você pode ter um diálogo mais significativo com alguém na Austrália do que com alguém no outro lado do corredor, e manter o contato com a mesma facilidade. Você pode apropriar-se de um novo gênero ou identidade, para mascararse ou explorar 'eus' possíveis (STONE, 1991; DAY et al., 1996). Você pode experimentar novos tipos de relacionamento com as pessoas, ser tratado de maneira diferente por elas. Você pode espreitar e ouvir conversas em comunidades em que algum dia pode ter desejado participar. Você pode ter uma degustação sem risco ou compromisso. E você ouvirá pontos de vista com os quais de outra forma não teria contato, ou avaliaria prematuramente de forma preconceituosa se tivesse identificado suas fontes em formas diferentes das que o ciberespaço possibilita.

Toda nova comunidade, toda comunidade transformada, potencialmente representa um novo letramento. Todo novo sistema de práticas convencionais para comunicações 
significativas já é um novo letramento, englobado em novas tecnologias. Todos os participantes em novas comunidades, em novas práticas sociais, potencialmente tornam disponíveis para nós novas identidades enquanto indivíduos e novas formas de humanidade enquanto membros de comunidades. Na medida em que a educação é iniciação em comunidades e especialmente em práticas de letramento genéricas e especializadas, novas tecnologias da informação, novas práticas de comunicação e novas redes sociais possibilitam novos paradigmas para a educação e a aprendizagem, e colocam em debate os pressupostos sobre os quais os paradigmas mais antigos se apoiam.

Práticas antigas migram em massa para sistemas ecossociais novos ou transformados: recriamos muito do que já é familiar. Nossos documentos de rede inicialmente se parecem com documentos impressos. Nossas comunidades online inicialmente se formam a partir de agrupamentos familiares institucionais. Mas nossos novos lares online vêm equipados com novos recursos, nossas práticas antigas assumem novos significados nestes novos cenários; novas oportunidades surgirão, novas surpresas se tornarão prováveis. Mudança e transformação estão em curso.

\section{TRANSFORMANDO LETRAMENTOS}

Quais são os novos letramentos que as novas tecnologias da informação estão tornando tanto necessários quanto possíveis? Os letramentos genéricos da Era da Informação certamente incluirão (LEMKE, 1996): habilidades de autoria multimidiáticas, análise crítica multimidiática, estratégias de exploração do ciberespaço e habilidades de navegação no ciberespaço.

Porém, há também uma questão ainda mais importante a ser considerada. Como podemos compreender o que elas demandam de nós e como adotá-las ou adaptá-las pode transformar as relações e as estruturas sociais? Discutirei abaixo alguns temas amplos que vão além das habilidades específicas de letramento e que acredito definirão as transformações mais radicais que as novas tecnologias podem trazer para o letramento e para a educação letrada.

\section{LETRAMENTOS MULTIMIDIÁTICOS}

Habilidades de autoria multimidiática e análise crítica multimidiática correspondem de forma aproximada a habilidades tradicionais de produção textual e de leitura crítica, mas precisamos compreender o quão estreita e restritiva foi, no passado, nossa tradição de educação letrada para que possamos ver o quanto a mais do que estamos dando hoje os estudantes precisarão no futuro. Nós não ensinamos os alunos a integrar nem mesmo desenhos e diagramas à sua escrita, quanto menos imagens fotográficas de arquivos, vídeo clips, efeitos sonoros, voz em áudio, música, animação, ou representações mais especializadas (fórmulas matemáticas, gráficos e tabelas etc.). Para estes tipos de produções multimidiáticas, isso não faz nem mesmo mais sentido, se é que em algum momento fez, falar em integrar estas outras mídias 'na' escrita. $\mathrm{O}$ texto pode ou não pode formar a espinha 
organizadora de um trabalho multimidiático. O que realmente precisamos ensinar, e compreender antes que possamos ensinar, é como vários letramentos e tradições culturais combinam estas modalidades semióticas diferentes para construir significados que são mais do que a soma do que cada parte poderia significar separadamente. Tenho chamado isto de 'significado multiplicador' (Lemke 1994a; 1998) porque as opções de significados de cada mídia multiplicam-se entre si em uma explosão combinatória; em multimídia as possibilidades de significação não são meramente aditivas.

Pelo menos funciona assim em princípio. Na prática, todo gênero multimidiático, toda tradição de letramento multimidiática, restringe o enorme conjunto de possibilidades para apenas algumas combinações permitidas ou favorecidas, mas há ainda sempre mais do que alguém poderia obter apenas adicionando aquelas mídias separadamente. Nenhum texto duplica exatamente o que uma figura significa para nós: texto e figura juntos não são duas formas de dizer a mesma coisa; o texto significa mais quando justaposto à figura, e da mesma forma a figura quando colocada ao lado de um texto.

Precisamos também perceber que estas habilidades multimidiáticas não são habilidades 'avançadas' que devem apenas ocorrer após a aprendizagem separada dos letramentos midiáticos. As primeiras formas de comunicação usadas pelas crianças integram articulações vocais com gestos motores amplos; elas aprendem, apenas gradualmente, a diferenciar gestos de desenho e desenho de gestos, entendendo-os como sistemas independentes para a construção de significados. Elas estão perfeitamente prontas para aprender letramentos multimidiáticos integrados bem desde o princípio, e é claro que elas o fazem: elas aprendem a ler livros de imagens enquanto conversam com adultos e brincam com objetos parecidos com as imagens nos livros. Elas começam a escrever e desenhar enquanto contam histórias e deixam traços de seus gestos no papel, nas paredes nas portas das geladeiras (cf. HICKS e KANEVSKY, 1992; DYSON, 1991; LEMKE 1994a). Mas nossas teorias e ensino do letramento têm sido desde há muito logocêntricos. Enquanto as crianças estão aprendendo a distinguir recursos semióticos diferentes (por exemplo, desenhando e escrevendo) e portanto dando vazão a espaços combinatórios mais amplos para usá-los de formas coordenadas, nós estamos apenas ensinando-as a usar um deles: a escrita. Quando nós de fato ensinamos outras modalidades, como cantar, desenhar ou fazer mímica, nós ainda não ensinamos os alunos sobre as tradições e possibilidades para combiná-las com a escrita e vice-versa. Isto precisa mudar, muito rápida e profundamente, se queremos ajudar os alunos a desenvolverem letramentos multimidiáticos sofisticados. Suas novas habilidades de autoria, espera-se, poderão habilitá-los a criar portifólios multimidiáticos (cf. KIEFFER et al., 1998) que ajudarão a nós, professores, remover os preconceitos logocêntricos de nossas avaliações de suas compreensões e competências, assim como os habilitará a produzir os tipos de significados que eles realmente querem construir.

Do mesmo modo, habilidades interpretativas críticas devem ser estendidas da análise de textos impressos para vídeo ou filme, de fotos de notícias e imagens de propagandas para quadros e tabelas estatísticos e gráficos matemáticos. Devemos ajudar os alunos a compreenderem exatamente como ler o texto de forma diferente e interpretar a imagem de forma diferente, em função da presença um do outro. Nós precisamos até mesmo compreender como é que sabemos qual texto é relevante para a interpretação de qual imagem e vice-versa. Tudo isto requer, ao menos para professores e especialistas da mídia, uma compreensão útil de semiótica multimidiática. 
Estou neste momento tentando desenvolver uma teoria geral de multimídia baseada na verificação do funcionamento de três universais semióticos: Apresentação (criar ou descrever o mundo), Orientação (tomar partido em relação à Apresentação ou a suas audiências) e Organização (ligar as partes ao todo), baseados_nos recursos de cada modalidade semiótica disponível (língua, tipografia, imagens, música etc.) para produzir um efeito de significação (LEMKE, 1989b, 1995b, 1998). Por exemplo, a representação imagética em pinturas apresenta o mundo, mas a perspectiva figurativa orienta para uma visão do mundo e a composição de massas e vetores de bordas e linhas organizam suas partes em um todo coerente. No texto, apresentamos conteúdo proposicional, orientamos com modo (comando vs. pergunta) e modalidade (pode vs. deve) e organizamos com estrutura genérica (introdução, desenvolvimento, conclusão) e coesão (João... se torna... ele...).

Outros trabalhos em semiótica social também contribuem para esta compreensão (por ex. O'TOOLE, 1990, 1994; KRESS e Van LEEUWEN, 1996). Com um modelo como este, funcionalmente motivado para a descrição do que é possível em multimídia, deveria ser possível não apenas analisar trabalhos multimidiáticos particulares, mas também comparar diferentes perspectivas e tradições em termos de quais possibilidades elas fazem uso e de quais não fazem. Devemos até mesmo ser capazes de identificar novas combinações que valham a pena ser experimentadas.

Tanto as habilidades de autoria, quanto as habilidades críticas e interpretativas voltadas à multimídia transformam potencialmente não apenas a forma como estudantes e professores comunicam suas ideias, mas também as formas como aprendem e ensinam. KINZER e RISKO (1998) falam da forma como professores iniciantes podem aprender através da análise multimidiática de suas experiências iniciais com o ensino. GOLDMAN-SEGALL (1992) e TIERNEY e DAMARIN (1998) realizam estudos de caso análogos sobre a forma como estudantes aprendem através da produção multimidiática. Nos dois casos, a integração do vídeo com o realismo pictórico, promovendo contexto e complexidade, com análise textual, promovendo foco e conceitualização, ajudam a definir e transformar os pontos de vista sobre as experiências dos outros e as nossas próprias.

\section{LETRAMENTOS INFORMÁTICOS}

Os letramentos da Era da Informação não são apenas sobre fazer e usar a multimídia. Eles também incluem 'letramentos informáticos': as habilidades do usuário de biblioteca e do usuário de texto. Habilidades para categorizar e localizar informações e objetos e apresentações multimidiáticos. O ciberespaço será muitas coisas: o último dos shopping centers, o parque de diversões mais sedutor, a universidade da universidade e principalmente, do ponto de vista do letramento, a biblioteca das bibliotecas. Estratégias de pesquisa e devolução de livros serão substituídas pela arte da exploração e da navegação; vamos substituir uma metáfora através da qual os textos chegam até nós (por exemplo, descarregando-os através de servidores remotos) para uma em que nós chegamos até eles (navegando através de mundos virtuais 3D que representam os servidores e seus conteúdos). Que estratégias são uteis para descobrir que tipos de conhecimentos existem no mundo? Como vasculhamos livrarias no ciberespaço? Uma vez definida uma área de interesse, 
como a exploramos sistematicamente? E uma vez que você decida aonde quer ir, o que você precisa saber para chegar lá? Os bibliotecários passaram anos aprendendo como a informação é classificada e organizada de acordo com convenções de uma centena de disciplinas e áreas de interesse. O que eles sabem que todos nós precisamos saber? E como podemos representar a topografia da informação de modos que facilitem para todos nós navegar em torno dela?

Sem todas estas habilidades, os futuros cidadãos estarão tão desempoderados quanto aqueles que hoje não escrevem, leem ou usam a biblioteca. Estas são as habilidades necessárias para nossos letramentos futuros, aquelas de que todos nós precisaremos. Porém, as novas tecnologias da informação também abrem novas possibilidades para ampliar nossos letramentos em novas formas e muitos de nós escolheremos desenvolver tipos adicionais de letramentos de que talvez nem todos precisem, mas que trarão grandes benefícios para aqueles que os adquirirem. Discutirei, a seguir, duas categorias potencialmente importantes desses letramentos de 'valores adicionais': letramento matemático-quantitativo e letramento intercultural.

\section{SIGNIFICADO TIPOLÓGICO E TOPOLÓGICO}

A análise da semiótica multimidiática me levou a refazer algumas perguntas antigas de maneiras novas e a começar a olhar para a história da escrita, do desenho, do cálculo e da mostra visual de imagens em uma perspectiva diferente (LEMKE 1994a, 1998). Estou começando a acreditar que construímos significados fundamentalmente de duas formas complementares: (1) classificando as coisas em categorias mutuamente exclusivas e (2) distinguindo variações de graus (ao invés de variação de tipo) ao longo de vários contínuos de diferença. A língua opera principalmente no primeiro, que chamo de tipológico. A percepção visual e a gesticulação espacial (desenhar, dançar) operam mais no segundo, a forma topológica. Como já argumentei, a construção real do significado geralmente envolve combinações de diferentes modalidades semióticas e também combinações bastante gerais destes dois modos. A semântica das palavras na língua é principalmente categorial ou tipológica em seus princípios, mas as distinções visuais significantes na escrita manuscrita (por exemplo, letras mais escuras ou um pouco mais grossas) ou na caligrafia, ou os efeitos acústicos da fala, um pouco mais alto ou forte, fazem sentido em um espectro contínuo de possibilidades, 'topologicamente'. (Na matemática, a topologia estuda questões sobre proximidade relativa, ligações, continuidade etc.) Mesmo em áreas especializadas como as ciências, a matemática, a arte ou a música, a pedagogia tem-se seguido uma tradição logocêntrica, enfatizando-se categorias conceituais e distinções semânticas e negligenciando-se a educação dos estudantes sobre princípios topológicos de construção do significado pela criação e interpretação de diferenças de graus e diferenças de tipos. Acredito que as novas tecnologias multimidiáticas tornarão muito maiores a saliência e importância dos tipos topológicos de significado e que uma ênfase nestes dois modos complementares de construção do significado pode ajudar os estudantes a captarem tipos de significados (por exemplo, aqueles baseados no raciocínio quantitativo e matemático) que iludiram muitos de nós no passado. 
O que é que figuras, desenhos, diagramas, gráficos, tabelas e equações fazem por nós que o texto verbal não pode fazer por si mesmo? O que podemos fazer ainda muito melhor quando combinamos textos com estas outras mídias? O que é que há exatamente em uma figura que mil palavras não podem expressar tão apropriadamente? Ou em um diagrama e seu título que nos dizem muito mais do que um desenho ou um texto sozinho poderia dizer? Por que a ciência natural escolheu falar com tanta frequência a linguagem da matemática? E a matemática é mesmo uma 'linguagem'? Deveriam os letramentos matemático e quantitativo ser considerados partes integrantes do letramento multimidiático para hoje e para amanhã?

Para responder a estas questões facilita se distinguir estes dois tipos de significados, ou estratégias para a construção do significado, que todas as culturas humanas parecem ter desenvolvido. Construímos significado contrastando tipos ou categorias de coisas, eventos, pessoas, signos. Por exemplo, distinguimos a direita da esquerda, a direção para cima da direção para baixo, o masculino do feminino, fruta de vegetal, movimento de estagnação, vermelho de azul, x de y, aaaa de oooo, comprar de vender, viver de morrer, escrever de desenhar. Esta é a base da semântica da língua natural e das representações análogas de tipos identificáveis, tipos, categorias, qualidades e assim por diante, em outras mídias. A maioria se constrói na lógica do ‘ou isso ou aquilo'. Em uma categoria, podemos frequentemente distinguir e contrastar muitas subcategorias diferentes até grandes 'delicadezas' de categorizações e descrições tipológicas. Nossas frases verbais constroem um número pequeno de relações semânticas entre processos categoriais, participantes e circunstâncias (cf. HALLIDAY, 1985; MARTIN, 1992), e disto vem nosso raciocínio conceitual. Mas esta não é a história completa da significação humana.

Algumas destas distinções categoriais também permitem diferenças de grau, tanto que há agora a possibilidade de casos intermediários que são em algum sentido mensuráveis ou quantitativos 'entre' outros: mais alto e mais baixo, mais perto e mais longe, mais rápido e mais devagar, mais laranja avermelhado. Mas não há nada entre movimento e estagnação, vida e morte; nenhuma mistura das letras x e y. A língua reconhece de fato a diferença de grau, mas tem muito poucos ou limitados recursos para descrever tais diferenças. Outras formas de ação humana significativa, no entanto, são maravilhosas para apontar indícios de graus intermediários: o levantar de uma sobrancelha, a tensão na voz, a largura de um gesto, a profundidade de um arco. Espaço e tempo; movimento, posição e ritmo definem para nós a possibilidade de significados que são mais topológicos, ligados ao grau, ou quase a mesma coisa e só um pouquinho mais ou menos, do que é parecido porque está próximo ou é quase igual a, mais do que parecido por possuir ou não possuir certas propriedades de critérios para enquadrar-se em uma categoria, por ser de algum tipo. Os significados tipológico e topológico são complementares de modos que são fundamentais.

Em função de a língua ser tão fortemente parcial em relação à construção de significados tipologicamente fundamentados, ela requer parceiros complementares que sejam melhores na construção de significados topológicos, especialmente quando o que estamos tentando compreender é um fenômeno que se altera de forma significativa através do grau. Você não pode descrever prontamente em palavras a forma de um parafuso de construção pendurado, mas pode gesticular sua forma e pode desenhá-lo (se você aprendeu essa habilidade). Se o formato representa dados sobre a pressão em diferentes lugares dentro de um sistema reator nuclear, não é suficiente dizer que a pressão está aumentando rapidamente perto da 
cúpula de confinamento: você quer medir a taxa de aumento e extrapolá-la gráfica e algebricamente.

Muitos fenômenos culturais parecem ser estritamente tipológicos, mas a análise topológica ou quantitativa pode diminuir essa ilusão (por exemplo, a biologia não encontra base quantitativa para as categorias raciais). Aprendemos a perceber tipologicamente outros fenômenos (como os fonemas ou nossa língua nativa), ainda que uma análise topológica ou quantitativa possa ser aprendida para percebermos tipologicamente, mesmo que uma análise topológica ou quantitativa possa ser fortemente pressionada para ver assim (por exemplo, o espectro acústico dos sons da língua na tela de um osciloscópio não se encaixa perfeitamente em categorias fonéticas e então você não pode 'ver' em que lugar letras particulares ou mesmo sílabas inteiras começam ou terminam - e algumas vezes não pode vê-las de forma alguma). Muitos fenômenos naturais, no entanto, levam quase que diretamente para a análise por meio do grau, no espaço, no tempo, em movimento ou mudança, em massa, temperatura e em todas as outras 'variáveis' quantitativas que a ciência tenha achado útil para tanto.

Nossos conceitos tendem a depender da semântica tipológica da língua ou de outro meio de representação, mas nossa experiência no mundo como corpos materiais no espaço e no tempo interagindo com o ambiente mostra-nos a importância que também tem o significado topológico. Não é por acaso que a extensão mais sistemática da língua natural em domínios topológicos de significado, conhecida por nós como matemática, emergiu historicamente como uma ponte entre a linguagem conceitual e a mensuração e descrição quantitativas. Ou que a matemática seja construída pelos dois lados: da língua através da aritmética à álgebra e às funções, e da variação contínua no espaço à representação visual, aos diagramas geométricos e gráficos cartesianos. A unificação moderna da álgebra e da geometria é apenas um capítulo na longa história da integração semiótica dos significados tipológicos e topológicos.

Muitas pessoas experienciam grande dificuldade com o raciocínio quantitativo e matemático, começando já por aqueles pontos em que, historicamente, a matemática foi além daquilo com que a língua natural poderia confortavelmente lidar, inventando noções como os raios complexos e as frações, compensando parcialmente as operações e reciprocidades-inversas, continuamente variando funções e equações com fatores e operações múltiplos. A língua natural não tem problemas com inteiros, com frações ou raios simples, com adição e subtração. Pode chegar muito forçosamente em torno da multiplicação e começa a desistir na divisão. Muitos conceitos matemáticos que são confusos ou resistem à explicação fácil e à aprendizagem apenas pela língua natural tornam-se muito mais claros com as representações visuais e manipulações combinadas com a língua natural. Não é o caso de substituir um pelo outro, mas de combiná-los: raciocínio tipológico e explicação topológica quantitativa.

Nem todo aspecto da vida cultural humana requer raciocínio matemático quantitativo sofisticado. Esta não é ainda parte das habilidades de letramento da maioria dos gêneros não técnicos. Para muitos propósitos, a combinação das representações visual-imagética, incluindo aquelas abstratas, como gráficos e tabelas, e representações verbais são suficientes. Mas suspeito que estender o letramento multimidiático para incluir representações matemáticas poderia tornar-se muito mais fácil com as novas tecnologias 
da informação. $\mathrm{O}$ uso expandido e a familiaridade com representações visuais tornará mais fácil para os estudantes lidarem com relações quantitativas expressas também em termos matemáticos mais formais (numérico e algébrico). Se chegar o tempo em que o letramento multimidiático de uma nova geração estiver tão à vontade com o raciocínio e a representação quantitativos assim como com descrição e com texto verbal, então simplificações ideológicas baseadas em nomes puramente categóricos, como Branco vs. Negro, Hétero vs. Gay, Masculino vs. Feminino serão vulneráveis à desconstrução quantitativa para muito mais pessoas do que alguns especialistas que entendem estes argumentos hoje. As culturas, os posicionamentos e as características das pessoas reais nunca couberam nas categorias estreitas de nossas tipologias e estereótipos. Muitas das pessoas reais têm reclamações, até certo ponto e de certo modo, para adequar-se aos dois lados dessas dicotomias, para serem membros de muitas categorias cujos nomes e definições os façam parecer mutuamente exclusivos. Nossas realidades vividas não podem ser representadas fielmente de maneira tipológica; muitas pessoas não têm voz onde não há outras formas de fazer sentido. $\mathrm{O}$ potencial topológico do letramento multimidiático pode ajudar a dar voz, dignidade e poder para pessoas híbridas reais. Pode minar um sistema ideológico que limita identidades pessoais a algumas caixinhas disponíveis e socialmente aprovadas, permitindo-nos ver e mostrar uns aos outros o universo de possibilidades humanas reais muito mais amplo e multidimensional.

\section{LETRAMENTOS CULTURAIS GLOBAIS}

A troca de informações, a colaboração acadêmica e nos negócios e até mesmo a diversão e as compras tornar-se-ão brevemente muito mais globais e interculturais do que já foram na história humana. A dominação do ciberespaço pelas tribos euro-americanas viverá, inevitavelmente, pouco. Sociedades asiáticas têm a tecnologia e a confiança em suas tradições culturais para garantir que a troca global não se realizará inteiramente em nossos termos, como aconteceu nos últimos séculos. Podemos não recepcionar bem a perda da hegemonia econômica e de nosso padrão de vida incomensuravelmente exagerado em relação ao resto da população mundial, mas devemos certamente recepcionar bem novas formas de construir significados. O inglês pode ou não sobreviver como a 'língua franca' da internet (depende muito de a tradução automática tornar-se efetiva, rápida e barata) e, embora isso não deva machucar os estadunidenses, particularmente, para aprenderem uma língua que não seja indo-europeia com uma escrita não alfabética, o que parece mais provável é que as tradições não europeias de projetos visuais e estéticos, por exemplo, os hibridismos asiático-europeus na multimídia, tornem-se extremamente importantes para os gêneros em desenvolvimento no ciberespaço. Em tempo, outras tradições culturais vão integrar-se à mistura de formas substanciais, assim como os hibridismos africano-europeus já fazem nos estilos musicais e nas artes visuais.

De forma crescente, membros das nossas comunidades online virão de histórias culturais que não são europeias ou estadunidenses. Precisaremos aprender a nos comunicar efetivamente com eles e a aprender efetivamente a partir deles. Nosso sucesso econômico, nossas oportunidades intelectuais e talvez a longa causa da paz e harmonia mundiais 
dependam do nosso sucesso nisto. Por termos estado no topo por tanto tempo, será mais difícil para muitos estadunidenses e europeus de classe média e alta aprender a ouvir através das diferenças culturais. A maioria do resto do mundo tem aprendido a nos ouvir há um bom tempo.

Conforme enfrentamos as várias tarefas de comunicação e projeção, de combinação e integração de imagens textuais e gráficas, ambas abstratas e icônicas, sem mencionar as animações, os vídeos, o som, entre outros, nós quereremos considerar todos os recursos, todas as tradições, todas as possibilidades no repertório humano. E precisaremos fazer isso conforme a próxima fase da evolução cultural mundial se acelere. Moveremo-nos para além da era das culturas nacionais e étnicas, para a era dos hibridismos culturais diversos, cada qual com sua comunidade global de membros e aficcionados. A nova ordem cultural mundial não será menos diversa e complexa do que a atual, mas sua base se expandirá através da geografia e da herança familiar para incorporar interesses compartilhados e a participação em comunidades centradas em atividades (ver exemplos em TIERNEY e DAMARIN, 1998).

A herança humana global promove mais do que uma diversidade guiada culturalmente como recurso para novas formas de construir significado: também promove a diversidade histórica dentro de cada tradição cultural. As formas visuais e textuais e as convenções para combiná-las passaram por muitas mudanças históricas interessantes, algumas delas amplamente perdidas para a consciência dos dias de hoje.

O estudo da história da mídia semiótica deverá se tornar cada vez mais uma parte importante da academia e um recurso mais rico para o currículo. No meu próprio trabalho, fiquei enormemente impressionado pelo que pode ser aprendido do rico recurso de uma história global e abrangente das notações matemáticas (CAJORI, 1928), ou da literatura crescente sobre a história das representações em muitos campos (por exemplo, ALPERS, 1983; BELLONE, 1980; EISENSTEIN, 1979; SKELTON, 1958; TUFTE, 1983, 1990; ver também OLSON, 1994, capítulo 10). Tão vasta quanto é esta literatura pouco apreciada, existe mais ainda sobre as convenções não-ocidentais das culturas. Tanto a história da mídia ocidental quanto da mídia não-ocidental provavelmente recompensarão fortemente, na minha opinião, o estudo, a apreciação e a a apropriação com o objetivo de construir e ensinar nossos futuros letramentos multimidiáticos.

Estas são as direções chave para a transformação de nossos letramentos contemporâneos enquanto entramos na Era da Informação: certamente precisamos de habilidades de letramento multimídia e informáticos agora e provavelmente precisaremos de mais letramentos quantitativo-topológico e globais-históricos no futuro próximo.

\section{TRANSFORMANDO PARADIGMAS DE APRENDIZAGEM}

Com tanto para ser aprendido, precisamos pensar um pouco em como as novas tecnologias da informação podem transformar nossos hábitos institucionais de ensinar e aprender. Há dois paradigmas de aprendizagem e educação em disputa em nossa sociedade hoje e as novas tecnologias vão, acredito, mudar o equilíbrio entre eles significativamente (LEMKE 1994b). 
O paradigma de aprendizagem curricular é dominante em instituições tais como escolas e universidades. O paradigma curricular assume que alguém decidirá o que você precisa saber e planejará para que você aprenda tudo em uma ordem fixa e em um cronograma fixo. Este é o paradigma do capitalismo industrial e da produção de massa baseada na fábrica. Desenvolveu-se simultaneamente a eles e em acordos filosóficos muito próximos; dá suporte às suas redes mais amplas de emprego e carreira e se assemelha a eles em autoritarismo, planejamento de cima para baixo, rigidez, escala econômica e incompatibilidades gerais ao novo mundo baseado no 'capitalista veloz' (veja abaixo). Por parte dos alunos, há ampla recusa e resistência, e seus resultados finais promovem pouco mais de utilidade demonstrada no mundo não acadêmico do que promovem alguns letramentos textuais e certificados de membro da classe média.

O paradigma da aprendizagem interativa domina instituições como as bibliotecas e os centros de pesquisa. Assume-se que as pessoas determinam o que elas precisam saber baseando-se em suas participações em atividades em que essas necessidades surgem e em consulta a especialistas conhecedores; que eles aprendem na ordem que lhes cabe, em um ritmo confortável e em tempo para usarem o que aprenderam. Este é o paradigma da aprendizagem das pessoas que criaram a internet e o ciberespaço. É o paradigma mais do acesso à informação do que da imposição à aprendizagem. É o paradigma de como pessoas com poder e recursos escolhem aprender. Seu resultado final é geralmente satisfatório para o aprendiz e frequentemente útil para os negócios ou para a academia. Este é talvez também o paradigma do 'capitalismo veloz' (GEE 1996), em que as economias baseadas na produção e circulação de informações favorecem a mudança rápida de grupos de trabalho de indivíduos flexíveis engajados em projetos que produzem resultados na hora certa [just in time] para consumidores de nichos mercadológicos. E tende a produzir menos 'aprendizagem comum' entre os membros da sociedade, favorecendo a especialização em educação de artes liberais.

Estes dois paradigmas educacionais estão em conflito básico e muitos desapontamentos que as escolas não estão mais decididas a enfrentar - tecnologias da informação mediadas pelo computador - podem talvez ser associados a este conflito mais amplo e não reconhecido (HODAS 1994).

Hoje, o paradigma curricular está falhando desastrosamente nos Estados Unidos. Qualquer um que tenha gasto tempo em uma escola urbana, mesmo nas melhores, pode lhes dizer que as coisas vão pior do que os testes padrão e as estatísticas podem revelar. A maioria dos alunos realmente não vê utilidade naquilo que se quer que eles aprendam. Muitos sabem que não estão preparados para o programa de aprendizagem anual. O país está tentando desenvolver um currículo nacional em um momento em que apenas os elementos mais rudimentares da escola baseada na aprendizagem (digamos até o $8^{\circ}$ ano) são demonstravelmente de valor para a maioria dos cidadãos quando eles deixam a escola, e quando, para além disso, o que quer que alguns irão utilizar outros não vão precisar de forma alguma. Estamos tentando impor aprendizagens uniformes em um tempo em que nunca houve desigualdades mais radicais de todos os tipos entre os alunos de uma determinada idade. Felizmente, os arranjos institucionais para as escolas nos Estados Unidos são tão descentralizados que o currículo nacional, na prática (em oposição aos acordos de princípio) parece improvável de realmente acontecer. Acredito que o esforço para criar um currículo nacional uniforme e centrado no conteúdo pode na verdade seriamente 
comprometer nossa transição para modelos educacionais mais efetivos e apropriados para o futuro globalmente competitivo.

O que parece estar geralmente acordado entre os educadores e muitos cidadãos e empregadores potenciais é que queremos que as pessoas, de qualquer idade, possam guiar sua própria aprendizagem, tenham conhecimento suficiente para saber como aprender mais, incluindo onde e a quem elas devem recorrer_ para obter conselhos úteis e informações relevantes. Queremos pessoas que sabem coisas que querem saber e pessoas que sabem coisas que são úteis em práticas fora das escolas. Queremos pessoas que sejam pelo menos um pouco críticas e céticas quanto à informação e aos pontos de vista e tenham alguma ideia de como julgar suas convicções. Mas além disso não há consenso social geral sobre o conteúdo da educação para além do que poderia ser aprendido nos oito ou nove primeiros anos de escola e não há base de pesquisa empírica para decidir o que cada cidadão poderia de fato achar útil saber depois de deixar a escola. Minha visão pessoal é que se tal pesquisa fosse feita não se acharia muito de universalmente necessário além do que pode ser ensinado nesses anos básicos. Talvez seja a hora de deixar para trás a preocupação estadunidense com a construção da nação e da cultura comum. Estamos indissoluvelmente ligados por nossas interações e interdependências uns dos outros, e realmente não interessa, exceto por questões ideológicas, o_quão_semelhantes nós somos ou somos ensinados a fazer de conta que somos.

Todo esforço para construir um currículo comum é um esforço de algumas pessoas para impor seus valores àqueles que provavelmente não concordam. Somente a necessidade demonstrada ou a utilidade substancial para a maioria das pessoas pode justificar moralmente uma uniformidade curricular, especialmente no contexto de um sistema educacional coercitivo (isto é, em que a participação não é voluntária e a resistência é punida por sanções que vão além das consequências inevitáveis de nossas próprias ações). Em particular, é moralmente questionável que a educação curricular seja imposta aos membros mais fracos da nossa sociedade: aqueles a que estão proibidos muitos direitos políticos e legais, apenas por causa de suas idades. Adultos empoderados não tolerariam as falhas_de muitas de nossas escolas: seu autoritarismo, sua incompetência educacional, seus recursos inadequados, suas condições físicas. Os mais jovens não têm muita escolha quanto a seu desamparo; eles não podem ainda operar a máquina da nossa complexa sociedade ainda que nos níveis mais básicos. Não podemos empoderá-los. Mas entre 10 e 13 anos, dependendo do indivíduo (e direcionado pelo menos um pouco pela quantidade de oportunidades obtidas), sabemos que um número cada vez maior de cidadãos jovens pode exercer direitos de adulto e o querem, mas não conseguem permissão para isso e, através da lei e da força, que consigam. Pode-se dizer que o paradigma curricular sobrevive em nossas escolas principalmente em função e, talvez em parte, a serviço da dominação política dos cidadãos em sua segunda década de vida por adultos mais velhos e mais poderosos.

Novas tecnologias da informação tornarão possível aos alunos aprender o que querem, quando querem, da forma como querem, sem as escolas. Nem todos os alunos terão acesso igual ou até mesmo imediato a estas tecnologias (cf. BRUCE e HOGAN, 1998), mas aqueles que o tiverem certamente verão as possibilidades. A educação curricular não poderá competir, para a eficácia educacional pura ou a eficiência econômica, com os serviços de aprendizagem que se tornarão disponíveis online em mídias portáteis para educação interativa. O paradigma 
interativo não precisa ser o de uma aprendizagem isolada, nem mesmo de uma aprendizagem mediada pelo computador. A interação social entre colegas e entre aprendizes e mentores e outros especialistas acontecerão online, entre duas pessoas e em grupos de vários tamanhos. Algumas dessas interações serão vividas em tempo real e algumas serão assíncronas como em listas de servidores e grupos de notícias. Grupos face-a-face ainda terão um importante papel uma vez que direcionarão a interação com professores. Mas as proporções de tempo gastas em cada um destes modos de aprendizagem mudarão radicalmente e a diversidade de perspectivas sobre a aprendizagem aumentará (GARNER e GILLINGHAM, 1998).

O que será necessariamente diferente de forma radical, no entanto, é a questão do controle. No paradigma interativo os estudantes assumem tópicos e interesses, problemas e compromissos deles próprios ou dos grupos dos quais participam. Eles encontrarão as categorias fundamentais, conceitos e princípios de todas as disciplinas básicas e, seja qual for a trilha que eles escolherem percorrer através das florestas do conhecimento, precisamente porque essas noções são de fato fundamentais e amplamente aplicáveis e portanto serão necessariamente encontradas aonde quer que viajemos. Mas todos eles irão procurar para si mesmos uma educação essencialmente diferente, apenas com esse grau de compartilhamento que vem da interação com os outros e da utilidade comum das noções comuns.

Uma vez que sua infra-estrutura tecnológica de informação esteja colocada, o paradigma de aprendizagem interativo será também muito provavelmente muito mais barato do que os arranjos curriculares das escolas atuais. Não precisaremos de uma infra-estrutura material educacional separada perto do que precisamos hoje; a educação será um dos propósitos de uma tecnologia multiobjetiva. Não precisaremos do tempo de trabalho de tantos professores, mas apenas compensar suficientemente as pessoas que ficarem à disposição para os alunos online e os poucos especialistas que vão prover facilidades de aprendizagem especializadas. Aqueles que produzem grandes ambientes de aprendizagem interativa serão bem pagos pelo mercado. Uma boa parte do potencial de trabalho produtivo que agora está amarrado ao currículo do giz e da fala para cativar as salas de aula serão liberados para enriquecer a economia da informação geral. Quais serão as novas tecnologias da informação que poderão apoiar melhor um paradigma de aprendizagem interativo e fazer uso desses letramentos multimidiáticos e informáticos que serão genuinamente necessários para todos?

\section{TRANSFORMANDO AS TECNOLOGIAS: SOBRE LETRAMENTOS METAMIDIÁTICOS}

A primeira geração das tecnologias de aprendizagem interativas foi, não surpreendentemente, uma simples transposição do modelo de educação do livro texto para uma nova mídia de demonstração. As árvores podem estar agradecidas, mas pouco muda em relação à natureza da aprendizagem, talvez apenas a motivação crescente para alguns alunos gerada pela novidade. Mas tão logo os textos online se tornem digitais (em oposição a imagens em bitmap da página), ele é facilmente pesquisável. E se pode ser pesquisável, 
pode ser indexado e estabelecer referência com outros textos. Agora, o texto é simultaneamente um banco de dados, e o hipertexto nasce (NELSON 1974, LANDOW 1992, BOLTER 1991 e 1998). Se podemos usar uma palavra ou frase no texto como um indexador para encontrar outras ocorrências e também adicionar referências para outros itens específicos em um mesmo texto, por que não fazer então ligações com outros textos? Nos casos mais simples, os hipertextos nos oferecem apenas um link por item, mas há uma limitação inerente a tipo no conceito ou tecnologia. Se podemos pular de um texto a outro, e para múltiplos pontos de aterrissagem em cada ponto de partida, precisaremos de alguma assistência para navegar e retroceder e ter uma noção do espaço textual que estamos projetando e atravessando. Como a topografia desses links não é linear, uma imagem ou mapa de duas ou três dimensões é uma ferramenta de navegação útil. Pode ser estabelecida por um autor e depois modificada e reconstruída pelo leitor.

Agora, a aprendizagem muda. Ao invés de sermos prisioneiros de autores de livros texto e de suas prioridades, escopos e sequência, somos agentes livres que podem encontrar mais sobre um assunto que os autores sintetizaram, ou encontrar interpretações alternativas que eles não mencionaram (ou com a qual concordam ou até mesmo consideram moral ou científico). Podemos mudar o assunto para adequá-lo ao nosso juízo de relevância para nossos próprios interesses e planos e podemos retornar mais tarde para um desenvolvimento padrão baseado no livro texto. Podemos aprender como se tivéssemos acesso a todos estes textos e como se tivéssemos um especialista que pudesse nos indicar a maioria das referências entre tais textos. Temos agora que aprender a realizar formas mais complexas de julgamento e ganhamos muita prática fazendo isso.

A próxima geração de ambientes de aprendizagem interativos adiciona imagens visuais e sons e vídeos, além de animação, o que se torna muito prático quando a velocidade e a capacidade de armazenamento podem acomodar estes significados densos de informação topológica. Do ponto de vista tipológico, o texto tem um nível muito_baixo de redundância, ele não textualiza mais do que o necessário para fazer as distinções chave entre uma palavra e outra. Já as imagens visuais tipicamente contêm todo tipo de informação tipológica 'irrelevante' - que é por este mesmo motivo potencialmente crítico a suas capacidades de significação topológicas. (Estratégias de compressão precisam ser muito cuidadosas para não serem parciais demais na preservação de significados tipológicos ao preço de significados topológicos de valor. Se você reduz o número de bites dedicado à mensagem de voz da tia Hilda da mesma forma como poderia fazer para sua mensagem de $e$-mail, você poderia provavelmente ainda discernir as palavras, mas não soaria mais como a tia Hilda). Estas mídias mais topológicas não podem ser indexadas e referenciadas por seu conteúdo interno (o que a figura mostra, por exemplo). Devem sim ser tratadas como 'objetos' inteiros. Mesmo assim, como objetos podem se tornar nós para hipertextos e, então, a hipermídia nasce (ver LANDOW e DELANY, 1991; BOLTER, 1998). A importância dos letramentos multimidiáticos correspondentes já foi discutida, mas ainda é importante notar que não é apenas o uso da hipermídia que as novas tecnologias tornam mais fácil, mas a sua autoria. Hoje, qualquer um edita um áudio ou um vídeo em casa, produz animações de boa qualidade, constrói objetos e ambientes tridimensionais, combina-os com textos e imagens paradas, adiciona música e voz e produz trabalhas muito além do que qualquer editora ou estúdio de cinema poderia fazer até alguns anos atrás. 
A chave para os paradigmas de aprendizagem interativos, no entanto, não são nem os hiperlinks nem a multimídia, mas a interação por si mesma. A mídia interativa apresenta a si mesma de forma diferente para diferentes usuários, dependendo das ações deles próprios. Isto pode ser tão simples quanto ver uma imagem ao invés de outra depois de clicar em um link, mas isso se torna útil em termos educacionais na medida em que o resultado das interações se acumula de maneira inteligente de tal forma que toda a história da minha interação com um programa influencia o que ele me mostra quando clico naquele link. Este é o princípio básico dos sistemas tutoriais inteligentes (STIs, ver WENGER, 1987), um desenvolvimento paralelo à hipermídia educacional, mas que está ainda muito dentro do paradigma curricular. Um programa STI constrói um 'modelo de usuário' ao longo do tempo e personaliza suas respostas para levar o usuário idealisticamente para um propósito de aprendizagem fixo. Cada usuário diferente segue caminhos potenciais diferentes, mas termina no mesmo lugar.

O que ganharíamos se combinássemos a personificação dinâmica do usuário de um STI com o paradigma de aprendizagem da hipermídia explorável e navegável? O propósito de um modelo de usuário não seria, então, criar um caminho de objetivos fixos; os objetivos poderiam ser emergentes para o usuário, como resultados de sua interação com as mídias. O modelo de usuário catalogaria os locais em que estivemos, nossos estilos de aprendizagem e preferências, nosso conhecimento prévio em diferentes assuntos e ofereceria uma série de escolhas filtradas para cada salto ou ligação que pudesse otimizar seus valores potenciais para nós. O programa poderia ser fixado para oferecer um escopo de escolhas mais limitadas ou amplas, indexar as opções através de vários critérios úteis para nossa própria escolha final e incluir um certo percentual de surpresas acidentais. Como um tutor humano, o programa 'nos reconheceria' e faria, de fato, sugestões para nos ajudar a fazer o máximo possível no ciberespaço. Poderia costurar para as nossas necessidades o texto e as imagens geradas (cf. HOVY, 1987). Também poderia, se necessário, reconfigurar informações de uma mídia a outra, até onde isso fosse possível, variando a relativa ênfase no texto, na voz, nas imagens paradas, nos vídeos, nas animações e em graus de abstração, tanto pela seleção dos itens disponíveis, quanto pela conversão de um no outro. Isto poderia, dessa forma, ser na verdade um sistema metamidiático.

Com este tipo de tecnologia poderíamos estar livres para aprender línguas e dialetos de nossa própria escolha, com estilos visuais e estéticos de nossa própria escolha, e misturando a mídia na qual aprendemos melhor. Assim como várias línguas documentais definidas (tais como SGML, HTML, e VRML; HOCKEY 1996) permitem browsers diferentes para personalizar como eles apresentam o mesmo texto e arquivos de imagens, pode-se imaginar que os arquivos de fonte de nosso sistema metamidiático conteriam dados em representações abstratas que poderiam ser apresentados em vários textos, quadros ou tabelas, gráficos, diagramas, imagens visuais, vídeo etc. (cf. ARENS, HOVY e VOSSERS, 1992), de acordo com a preferência do usuário e da recomendação do 'tutor' STI.

A fonte original da mídia será portanto religada e suas apresentações transformadas infinitamente por diferentes indivíduos e grupos de usuários que compartilham arquivos. Os sistemas precisarão guardar os passos das anotações e modificações dos usuários (versões antigas de cópias), links adicionados pelos usuários, transformações da mídia causadas pelos usuários, sequências definidas por eles etc., de forma que qualquer arquivo 
de fonte original ou trabalho metamidiático completo existirá em muitas versões personalizadas, cada qual com uma história passível de reconstrução. Algumas dessas versões se tornarão, de forma compreensível, mais populares com novos usuários do que as originais, e algumas poderão ser reconhecidas como 'clássicos', ainda que todas elas sejam infinitamente modificadas. Vários usuários de comunidades determinarão o que constitui ‘valor agregado' nesse processo, e o que é transitório ou idiossincrático. Sistemas tutoriais metamidiáticos inteligentes terão, obviamente, que ser capazes de escolher dentre as muitas versões disponíveis enquanto buscam otimizar para seus usuários. Os usuários ganharão, inevitavelmente, alguma sofisticação nesse processo enquanto fornecem ao 'tutor' instruções explícitas e respostas a questionamentos assim como padrões estatísticos das escolhas passadas e presentes, para as quais o programa tutorial será sensível.

\section{TRANSFORMANDO A HUMANIDADE}

A última mídia que se apresenta é a própria realidade: o que vemos e ouvimos, tocamos e sentimos; o que manipulamos e controlamos; onde sentimos que estamos presentes e vivos. Nossos corpos são parte integral de sistemas ecossociais mais amplos: vivemos nesses sistemas materialmente como sinais sensores e feedback de motores, trocas de calor e correntes de nutrientes/perdas nos ligam dentro deles; e vivemos neles semioticamente conforme construímos sentidos culturais e pessoais significativos da nossa participação. Lendo um texto, nossas imaginações verbais e visuais podem começar a formar um segundo mundo de significados somado aos costumeiramente reais. Assistir a um filme em uma tela ampla diminui a divergência entre dados sensoriais e ilusões ficcionais; podemos experimentar o terror ou a sensação de queda enquanto assistimos a uma tela de tecido e sentamos em uma cadeira fixa. É possível interceptar muitos dos sinais através dos quais nossos corpos se localizam no espaço, tempo e realidade e os substitui por outros sinais. Para fazermos isso, precisamos monitorar nossas ações e sinais motores divergentes assim como fornecer novos insumos, porque nossos corpos criam a realidade a partir da relação entre forças centrífugas e impulsos nervosos centrípetos. Um computador rápido o suficiente pode simular a realidade bem o suficiente para impor uma grande parte dos links desenvolvidos de nossos corpos com seus ambientes. Podemos criar realidades virtuais, e podemos sentir como se estivéssemos vivendo nelas. Podemos criar a sensação de presença total (cf. BENEDIKT, 1991; RHEINGOLD, 1991).

Em um ambiente de realidade virtual (RV), todas as outras mídias podem ser apresentadas e coordenadas. As tecnologias da RV adicionam uma interatividade mais ampla: podemos fazer mais coisas acontecerem nos mundos RV, e isso explica, em parte, por que sentimos que elas são mais reais. Mas elas não têm que ocorrer de acordo com as leis da física normal ou com as restrições de nosso ambiente ecológico normal, desde que o tempo da ação e reação seja preciso o suficiente fazê-las parecerem reais. Em princípio na RV podemos aprender fazendo, sem consumir recursos materiais proporcionais ao que precisaríamos no mundo normal, sem os riscos característicos da vida e do limbo, ou as consequências para nosso ecossistema de vida sustentável. E podemos fazer o que simplesmente não é 
normalmente possível: podemos mudar a realidade através de atos de vontade e de pequenos comandos motores, podemos ser as fontes de nossos sonhos e pesadelos.

Podemos também aprender a ser seres humanos diferentes. Podemos caminhar não através de um vale marciano simulado, mas pela telepresença e um sistema sensor robótico na superfície real de marte. Podemos sonar como as baleias ou planar como as águias. Podemos observar a Terra do espaço em tempo real e focar em qualquer lugar que seja visível e monitorado. Podemos observar as mudanças na floresta tropical através dos anos em nossas escalas de tempo humanas normais como são observadas a partir do espaço. Podemos fazer investigações com insetos. Podemos encontrar moléculas biológicas e fazer química com as mãos enquanto as moléculas reagem de acordo com as leis quânticas. Podemos expandir a escala da experiência humana direta no espaço e no tempo até o limite de nossas tecnologias. E podemos fazer tudo isso enquanto crianças.

Que tipo de humanidade é possível para nós se podemos aprender desses modos? Se temos estas experiências desde a infância? Quais são as possibilidades e quais são os perigos?

Os letramentos da RV convergem com, e de fato vão além, dos letramentos e sabedorias da própria vida humana. O que é 'letramento' quando a distinção entre 'ler' e viver se torna uma diferença de forma de nomear? Quando uma 'realidade' se torna nosso texto multimidiático, enriquecido pela fonte de hiperlinks que podem nos levar não apenas de uma página a outra ou de um texto a outro, mas de um lugar a outro, de um tempo a outro e de uma escala cosmológica para um mundo de quarks? Isto é sonho ou pesadelo?

Sim, podemos nos perder nesse ciberespaço. Não porque queiramos ou por necessidade de navegação, mas porque preferimos os mundos da nossa própria imaginação àqueles em que nos desenvolvemos. O letramento promove tanto o poder quanto a vulnerabilidade: o poder para adicionar um segundo mundo de significados ao mundo em que nossos corpos estão enredados, mas também a vulnerabilidade de confundir o primeiro com o segundo. O poder surge quando adicionamos um ao outro; o perigo, se substituímos a realidade virtual pela ecológica. A capacidade semiótica dos seres humanos nos faz infinitamente adaptáveis em termos dos significados que podemos somar à nossa experiência, mas nem todas essas possíveis adaptações permitirão que nossas espécies sobrevivam. No período de vida dos estudantes que estão agora em nossas escolas, estes assuntos precisarão ser encarados. Será que os letramentos que ensinamos hoje os ajudarão a fazer as escolhas mais sábias?

Ninguém pode prever as transformações do século XXI durante a revolução tecnológica da informação. Nós certamente não podemos continuar ensinando nossos estudantes apenas os letramentos da metade do século XX, ou simplesmente colocar na frente deles os letramentos mais avançados e diversos de hoje. Precisamos ajudar essa geração a aprender a usar sabiamente os letramentos e esperar que eles saiam-se melhor do que nós.

\section{REFERÊNCIAS BIBLIOGRÁFICAS}

ALPERS, S. (1983). The art of describing. Chicago: University of Chicago Press. 
ARENS, Y.; HOVY, E.; VOSSERS, M. (1992). On the knowledge underlying multimedia presentations. In: Maybury, M. (ed.) Intelligent Multimedia Interfaces. Stanford: AAAI Press, p. 280-306.

BAZERMAN, C. (1988). Shaping written knowledge. Madison, Wis.: University of Wisconsin Press. . (org.). (1994). Systems of genres and the enactment of social intentions. In: Freedman, A; Medway, P. (ed.). Genre and the new rhetoric. London: Taylor \& Francis, p. 79-101.

BEACH, R.; LUNDELL, D. (1998). Early adolescents' use of computer-mediated communication in writing and reading. In: Reinking, D. et al. (ed.), Handbook of literacy and technology: Transformations in a post-typographic world. Mahwah, N.J: Erlbaum, p. 93-112.

BELLONE, E. (1980). A world on paper: Studies on the second scientific revolution. Cambridge, MA: MIT Press BENEDIKT, M. (1991) Cyberspace: First steps. Cambridge, MA: MIT Press.

BOLTER, J. D. (1991). Writing space. Hillsdale, NJ: Erlbaum.

. (1998). Hypertext and the question of visual literacy. In: Reinking, D. et al. (ed.). Handbook of Literacy and Technology: Transformations in a post-typographic world. Mahwah, NJ: Erlbaum, p. 3-13.

BRUCE, B.; HOGAN, M. P. (1998). The disappearance of technology: Toward an ecological model of literacy. In: Reinking, D. et al. (ed.) Handbook of Literacy and Technology: Transformations in a Post-Typographic World. Mahwah, NJ: Erlbaum, p. 269-281.

BRYSON, M.; DeCASTELL, S. (1996). Learning to make a difference: Gender, new technologies and in/ equity. Mind, Culture, and Activity, 3(2), p. 119-135.

CAJORI, F. (1928). A history of mathematical notations. Chicago: Open Court Publishing.

DAY, M.; CRUMP, E.; RICKLY, R. (1996). Creating a virtual academic community. In: Harrison, T. M.; Stephen, T. D. (ed.) Computer networking and scholarship in the 21st-century university. Albany: SUNY Press, p. 291-314.

DERRIDA, J. (1976). Of grammatology. Baltimore, MD: Johns Hopkins University Press.

DYSON, A. H. (1991). Toward a reconceptualization of written language development. Linguistics and Education, 3, p. 139-162.

EISENSTEIN, E. (1979). The printing press as an agent of change. Cambridge: Cambridge University Press.

ENGESTROM, Y. (1990). Learning, working, and imagining. Helsinki: Orienta-Konsultit.

FOUCAULT, M. (1969). The archeology of knowledge. New York: Random House.

GARNER, R.; GILLINGHAM, M. G. (1998). The internet in the classroom: Is it the end of transmissionoriented pedagogy? In: Reinking, D. et al. (ed.) Handbook of literacy and technology: Transformations in a post-typographic world. Mahwah, NJ: Erlbaum, p. 221-231.

GEE, J. P. (1990). Social linguistics and literacies. London: Falmer Press. (1996). On mobots and classrooms. Organization, 3(3), p. 385-407.

GOLDMAN-SEGALL, R. (1992). Collaborative virtual communities. In: Barrett, E. (ed.) Sociomedia: Multimedia, hypermedia, and the social construction of knowledge. Cambridge, MA: MIT Press, p. 257-296. 
HALlidAY, M. A. K. (1977). Text as semantic choice in social context. In: Van Dijk, T. A.; Petöfi, J. (ed.) Grammars and descriptions. Berlin: de Gruyter, p. 176-225. . (1978). Language as social semiotic. London: Edward Arnold. (1985). An introduction to functional grammar. London: Edward Arnold.

HARAWAY, D. (1991). Simians, cyborgs, and women. New York: Routledge.

HARRIS, R. (1995). Signs of writing. London: Routledge.

HARRISON, T. M.; STEPHEN, T. D. (1996). Computer networking, communication, and scholarship. In Harrison, T. M.; Stephen, T. D. (ed.) Computer Networking and Scholarship in the 21st Century University. Albany: SUNY Press, p. 3-38.

HICKS, D.; KANEVSKY, R. (1992). Ninja Turtles and other superheroes: A case study of one literacy learner. Linguistics and Education, 4, p. 59-106.

HOCKEY, S. (1996). Computer networking and textual sources in the humanities. In: Harrison, T. M.; Stephen, T. D. (ed.) Computer Networking and Scholarship in the 21st Century University. Albany: SUNY Press. p. 83-94.

HODAS, S. (1994). Technology refusal and the organizational culture of schools. In: Cyberspace superhighways: Access, ethics, and control (Proceedings of the Fourth Conference on Computers, Freedom, and Privacy.) Chicago: John Marshall Law School, p. 54-75.

HOVY, E.H. (1987). Generating natural language under pragmatic constraints. Journal of Pragmatics, 11(6), p. 689-719.

HUTCHINS, E. (1995). Cognition in the wild. Cambridge, MA: MIT Press.

KIEFFER, R. D.; HALE, M. E.; TEMPLETON, A. (1998). Electronic literacy portfolios: Technology transformation in a first-grade classroom. In: Reinking, D. et al. (ed.). Handbook of literacy and technology: Transformations in a post-typographic world. Mahwah, NJ: Erlbaum, p. 145-163.

KINZER, C.; RISKO, V. KINZER, C.; RISKO, V. (1998). Multimedia and Enhanced Learning: Transforming Preservice Education. In: Reinking, D. et al. (ed.). Handbook of technology and literacy: Transformations in a post-typographic world. Mahwah, NJ: Erlbaum, p. 185-202.

KRESS, G., VAN LEEUWEN, T. (1996). Reading images: The grammar of visual design. London: Routledge.

LANDOW, G. P. (1992). Hypertext: The convergence of contemporary literary theory and technology. Baltimore; London: Johns Hopkins University Press.

LANDOW, G. P.; DELANY, P. (ed.) (1991). Hypermedia and literary studies. Cambridge, MA: MIT Press.

LATOUR, B. (1987). Science in action. Cambridge, MA: Harvard University Press. . (1993). We have never been modern. Cambridge, MA: Harvard University Press.

LAVE, J. (1988). Cognition in practice. Cambridge, UK: Cambridge University Press.

LEMKE, J. L. (1989a). Social semiotics: A new model for literacy education. In: Bloome, D. (ed.)

Classrooms and literacy. Norwood, NJ: Ablex Publishing, p. 289-309. (1989b). Semantics and social values. WORD, 40(1-2), p. 37-50.

(1993a). Discourse, dynamics, and social change. Cultural Dynamics, 6(1), p. 243-275. 
LEMKE, J. L. (1993b). Intertextuality and educational research. Linguistics and Education, 4(3-4), p. 257-268.

(1993c). Education, cyberspace, and change. [Artigo eletrônico para o Information Technology and Education Electronic Salon, Deakin University, Australia; publicado em EJVC: Electronic Journal on Virtual Culture, março de 1993. Disponível em: <http://serials.infomotions.com/aejvc/ aejvc-v1n01-lemke-education.txt $>$. Também disponível via ERIC Documents Service, Arlington VA: (E D356 767).]

(1994a). Multiplying meaning: Literacy in a multimedia world. [Artigo apresentado na National Reading Conference, Charleston SC (dez. 1993)]. Arlington VA: ERIC Documents Service (ED 365 940).

. (1994b). The coming paradigm wars in education: Curriculum vs. information access. In: Cyberspace superhighways: Access, ethics, and control. (Proceedings of the Fourth Conference on Computers, Freedom, and Privacy. Chicago: John Marshall Law School, p. 76-85.

. (1995a). Intertextuality and text semantics. In Gregory, M.; Fries, P. (ed.) Discourse in society: Functional perspectives. Norwood, NJ: Ablex Publishing, p. 85-114.

(1995b). Textual politics: Discourse and social dynamics. London: Taylor \& Francis.

. (1995c). Literacy, culture, and history: Review of The World on Paper. Communication Review, 1(2), p. 241-259.

(1996a). Hypermedia and higher education. In: Harrison, T. M.; Stephen, T. D. (ed.) Computer

Networking and Scholarship in the 21st Century University. Albany: SUNY Press, p. 215-232.

. (1996b). Emptying the center. Organization, 3(3), p. 411-418.

(1998). Multiplying meaning: Visual and verbal semiotics in scientific text. In: Martin, J. R.

(ed.) Reading Science. London: Routledge, p. 87-114.

(1997). Review of: Roy Harris. Signs of Writing. Functions of Language, 4(1), p. 125-129.

LYNCH, M.; WOOLGAR, S. (ed.) (1990). Representation in scientific practice. Cambridge, MA: MIT Press.

MARTIN, J. R. (1992). English text. Philadelphia: John Benjamins.

NELSON, T. H. (1974). Dream Machines/Computer Lib. Chicago: Nelson/Hugo's Book Service. [Republicado por Redmond, WA: Tempus, 1987.]

OLSON, D. R. (1994). The world on paper. Cambridge: Cambridge University Press.

O’TOOLE, M. (1990). A systemic-functional semiotics of art. Semiotica, 82, p. 185-209. , M. (1994). The language of displayed art. London: Leicester University Press.

PURVES, A. (1998). Flies in the web of hypertext. In: Reinking, D. et al. (ed.). Handbook of literacy and technology: Transformations in a post-typographic world. Mahwah, NJ: Erlbaum, p. 235-251.

REINKING, D.; MCKENNA, M.; LABBO, L.; KIEFFER, R. D. (ed.) (1998). Handbook of literacy and technology: Transformations in a post-typographic world. Mahwah, NJ: Erlbaum, 379p.

RHEINGOLD, H. (1991). Virtual reality. New York: Simon \& Schuster.

. (1993). The virtual community: Homesteading on the electronic frontier. Reading, MA: AddisonWesley.

ROGOFF, B. (1990). Apprenticeship in thinking. New York: Oxford University Press.

SKELTON, R.A. (1958). Explorers' maps: Chapters in the cartographic record of geographical discovery. London: Routledge \& Kegan Paul.

SOFIA (SOFOULIS), Z. (1995). Of spanners and cyborgs. In Caine, B.; Pringle, R. (ed.) Transitions: New Australian Feminisms. New York: St. Martin's Press, p. 147-163. 
STONE, A.R. (1991). Will the real body please stand up: Boundary stories about virtual cultures. In Benedikt, M. (Ed.), Cyberspace: First steps (pp.81-118). Cambridge, MA: MIT Press.

TIERNEY, R. J.; DAMARIN, S. (1998). Technology as enfranchisement, cultural transformation, and learning practices. In: Reinking, D. et al. (ed.) Handbook of literacy and technology: Transformations in a post-typographic world. Mahwah, NJ: Erlbaum, p. 253-268. . .

TUFTE, E. R. (1983). The visual display of quantitative information. Cheshire, Conn.: Graphics Press. (1990) Envisioning information. Cheshire, Conn.: Graphics Press.

UNSWORTH, J. (1996). Living inside the operating system: community in virtual reality. In: Harrison, T. M.; Stephen, T. D. (ed.) Computer Networking and Scholarship in the 21 st Century University. Albany: SUNY Press, p. 137-150.

WENGER, E. (1987). Artificial intelligence and tutoring systems. Los Altos, CA: Morgan Kaufmann Publishers.

WERTSCH, J. (1991). Voices of the mind. Cambridge, MA: Harvard University Press.

Traduzido por Clara Dornelles (UNIPAMPA/RS)

Recebido: $25 / 07 / 2010$

Aceito: 29/11/2010 
